\title{
Test Results From the PF Conductor Insert Coil and Implications for the ITER PF System
}

\author{
D. Bessette, Luca Bottura, A. Devred, N. Mitchell, K. Okuno, Y. Nunoya, C. Sborchia, Y. Takahashi, \\ A. Verweij, A. Vostner, R. Zanino, E. Zapretilina, and the PF Conductor Insert Test Group
}

\begin{abstract}
In this paper we report the main test results obtained on the Poloidal Field Conductor Insert coil (PFI) for the International Thermonuclear Experimental Reactor (ITER), built jointly by the EU and RF ITER parties, recently installed and tested in the CS Model Coil facility, at JAEA-Naka. During the test we (a) verified the DC and AC operating margin of the NbTi Cable-in-Conduit Conductor in conditions representative of the operation of the ITER PF coils, (b) measured the intermediate conductor joint resistance, margin and loss, and (c) measured the AC loss of the conductor and its changes once subjected to a significant number of Lorentz force cycles. We compare the results obtained to expectations from strand and cable characterization, which were studied extensively earlier. We finally discuss the implications for the ITER PF system.
\end{abstract}

Index Terms-Cable-in-conduit conductors, fusion reactors, $\mathrm{Nb}$-Ti superconducting material, superconducting magnets.

\section{BACKGROUND ON ITER PF CONDUCTORS}

$\mathbf{T}$ HE ITER Poloidal Field (PF) conductors have undergone a significant evolution in the past years. In the original ITER design (2001) the Cable-in-Conduit Conductors (CICCs) were optimized to match the current/field levels in each of the six PF coils [1]. Following recent design reviews, a number of modifications have been introduced [2], leading to the conductor designs detailed in Table I, for the envelope of operating conditions in the PF Coils reported in Table II. The main change with respect to the original design is a reduction in the $\mathrm{Cu}: \mathrm{nonCu}$ ratio of the low field conductors (PF2 to PF5), implying that the Stekly condition of cryogenic stability [3] is no longer respected. Experiments on subsize conductors [4] have suggested that in the planned regime of operation, and for the expected perturbation spectrum, full cryostability (i.e. a copper fraction corresponding to the Stekly limit) is excessive. In fact, for the conditions considered, it is more convenient to design the conductor for larger temperature margin, increasing the fraction of $\mathrm{Nb}-\mathrm{Ti}$, while maintaining the copper fraction to the strict minimum demanded for protection.

Manuscript received August 26, 2008. First published May 12, 2009; current version published July 15, 2009.

D. Bessette, A. Devred, and N. Mitchell are with ITER, Cadarache, France.

L. Bottura and A. Verweij are with CERN, Geneva, Switzerland (e-mail: Luca.Bottura@cern.ch).

K. Okuno, Y. Nunoya, and Y. Takahashi are with JAEA, Naka, Japan.

C. Sborchia and A. Vostner are with F4E, Barcelona, Spain.

R. Zanino is with Politecnico di Torino, Turin, Italy.

E. Zapretilina is with the Efremov Institute, St. Petersburg, Russia.

Color versions of one or more of the figures in this paper are available online at http://ieeexplore.ieee.org.

Digital Object Identifier 10.1109/TASC.2009.2017922
TABLE I

PARAMETERS OF ITER PF CICCS

\begin{tabular}{|c|c|c|c|}
\hline & PF1, PF6 & PF5 & PF2,PF3,PF4 \\
\hline Pattern & \multicolumn{3}{|c|}{$3_{\mathrm{SC}} \times 4 \times 4 \times 5 \times 63_{\mathrm{SC}} \times 4 \times 4 \times 4 \times 6\left(2_{\mathrm{SC}}+1_{\mathrm{Cu}}\right) \times 3 \times 4 \times 5 \times 6$} \\
\hline Central spiral & \multicolumn{3}{|c|}{$10 \times 12 \mathrm{~mm}$} \\
\hline Petal wrap & \multicolumn{3}{|c|}{$0.05 \mathrm{~mm}, 50 \%$ cover } \\
\hline Cable wrap & \multicolumn{3}{|c|}{$0.08 \mathrm{~mm}, 40 \%$ cover } \\
\hline $\mathrm{D}_{\text {strand }}(\mathrm{mm})$ & 0.73 & 0.73 & 0.73 \\
\hline $\mathrm{Cu}:$ non- $\mathrm{Cu}$ & 1.6 & 2.3 & 2.3 \\
\hline $\mathrm{D}_{\mathrm{Cu}, \mathrm{core}}(\mathrm{mm})$ & none & 2.85 & 2.70 \\
\hline SC strands & 1440 & 1152 & 720 \\
\hline $\mathrm{A}_{\text {non- } \mathrm{Cu}}\left(\mathrm{mm}^{2}\right)$ & $229.3^{(1)}$ & $144.5^{(1)}$ & $90.3^{(1)}$ \\
\hline $\mathrm{A}_{\mathrm{Cu}}\left(\mathrm{mm}^{2}\right)$ & $366.8^{(1)}$ & $370.5^{(1)}$ & $424.7^{(1)}$ \\
\hline $\mathrm{D}_{\text {cable }}(\mathrm{mm})$ & 37.7 & 35.3 & 35.3 \\
\hline
\end{tabular}

TABLE II

OPERATING ENVELOPE FOR THE PF CONDUCTORS

\begin{tabular}{lccc}
\hline Coil & $\begin{array}{c}\text { Temperature } \\
(\mathrm{K})\end{array}$ & $\begin{array}{c}\text { Current } \\
(\mathrm{KA})\end{array}$ & $\begin{array}{c}\text { Field } \\
(\mathrm{T})\end{array}$ \\
\hline PF2 & 4.7 & 55 & 4.8 \\
& & 50 & 5.0 \\
PF5 & 4.7 & 52 & 5.7 \\
& & 33 & 6.0 \\
PF6 & 4.5 & 48 & 6.4 \\
& & 41 & 6.5 \\
& $4.2^{(2)}$ & 52 & 6.8 \\
& & 41 & 7.0 \\
\hline
\end{tabular}

${ }^{(2)}$ subcooled operation planned for this set of conditions

To achieve the operating requirements of Table II, two main conditions must be met. Firstly, the cable performance must be close to the sum of the projected performance of the individual strands, without the occurrence of the premature quenches often seen in large size $\mathrm{Nb}$ - $\mathrm{Ti}$ conductors and attributed to current non-uniformity [4], [5] (see also later discussion). In practice, we quantify this first condition using the temperature margin above the operating temperature. The design value of the temperature margin is $1.5 \mathrm{~K}$, with a maximum uncertainty of $0.5 \mathrm{~K}$, which results in a minimum acceptable margin of $1 \mathrm{~K}$.

Secondly, all AC loss sources in the cable must be controlled, so to limit the temperature increase due to the heating due to the pulsed operation. In particular, the product of the cable demagnetization factor and coupling time constant, $\mathrm{n} \tau$, proportional to coupling loss, must be smaller than $100 \mathrm{~ms}$.

The two conditions above (sufficient margin and limited AC loss) were demonstrated in the test of the PF Conductor Insert coil (PFI), which is representative of the most demanding ITER PF coil, PF6. In addition, we explored the operating limits of the 
TABLE III

MAIN CHARACTERISTICS OF THE PFI WINDING

\begin{tabular}{ll}
\hline Inner diameter (m) & 1.40 \\
Outer diameter (m) & 1.57 \\
Height (m) & 1.40 \\
Weight (tons) & 6 \\
Operating temperature (K) & 4.5 \\
Nominal operating field (T) & 6 \\
Nominal operating current (kA) & 45 \\
Backup mode operating field (T) & 6.4 \\
Backup mode operating current (kA) & 52 \\
Maximum stored energy (MJ) & 0.2 \\
\hline
\end{tabular}

TABLE IV

MAIN CHARACTERISTICS OF THE PFI STRAND

\begin{tabular}{ll}
\hline Diameter $(\mathrm{mm})$ & 0.73 \\
SC material & Nb-47.5 wt $\% \mathrm{Ti}$ \\
Number of filaments & 2346 \\
Nominal filament diameter $(\mu \mathrm{m})$ & 9.8 \\
Cu:non-Cu ratio & $1.41+/-0.06(1 \sigma)$ \\
$I_{C}(5 \mathrm{~T}, 4.2 \mathrm{~K}, 0.1 \mu \mathrm{V} / \mathrm{cm})(\mathrm{A})$ & $489+/-10(1 \sigma)$ \\
$J_{C}(5 \mathrm{~T}, 4.2 \mathrm{~K}, 0.1 \mu \mathrm{V} / \mathrm{cm})\left(\mathrm{A} / \mathrm{mm}^{2}\right)$ & $2817+/-47(1 \sigma)$ \\
$n$ index & $54+/-7(1 \sigma)$ \\
RRR & $199+/-17(1 \sigma)$ \\
Nominal twist pitch $(\mathrm{mm})$ & $<10$ \\
Surface Ni-coating $(\mu \mathrm{m})$ & $2.2+/-0.3$ \\
\hline
\end{tabular}

conductor at lower fields, thus simulating the operating conditions of the PF2-PF5 conductors. In the following sections we give details on the PFI test insert, the motivation of the test program and highlights on the main results.

\section{THE PF CONDUCTOR INSERT}

The Poloidal Field Conductor Insert (PFI) is the main fullsize demonstration of the conductor and joint technology that will be applied to the ITER Poloidal Field (PF) Coils. The PFI is a single layer solenoid that has been designed and built for extensive testing in the CS Model Coil (CSMC) test facility at JAEA, Naka. Its main dimensions and nominal operating points are reported in Table III. The PFI solenoid is split in two parts. The main winding, consisting of 9 turns wound with approximately $45 \mathrm{~m}$ of $\mathrm{Nb}$-Ti CICC, is connected through an intermediate joint to an upper bus-bar, which is an additional turn of approximately $4.5 \mathrm{~m}$ length of the same CICC.

The main winding has a joggle in the midplane, largely instrumented with voltage taps, thermometers, a pressure tap, a pick-up coil and an inductive heater. This coil section is placed in the equatorial plane of the test facility to experience the peak field of the CSMC. The intermediate joint, further away from the midplane of the CSMC, experiences a field which is approximately $25 \%$ lower, with both vertical and radial components, as will be the case for the ITER PF coils.

The similarity between the CICC of the PFI and the one designed for the PF1 and PF6 is evident, comparing the data reported in Tables I, IV, and V. The PFI CICC has a similar strand (same diameter and $\mathrm{J}_{\mathrm{C}}$, but reduced $\mathrm{Cu}$ :Non-Cu ratio) and the same cable layout as the ITER PF1 and PF6. Further details on the coil design [6], strand and cable manufacturing [7]-[11], coil manufacturing [12], short sample test results [5], [13], and supporting analyses to the insert test [14]-[17] can be found in the extensive list of references quoted.
TABLE V

MAIN CHARACTERISTICS OF THE PFI CICC

\begin{tabular}{ll}
\hline Number of Nb-Ti strands & 1440 \\
Cabling pattern & $3_{\mathrm{SC} 44 \times 4 \times 5 \times 6}$ \\
Twist pitches $(\mathrm{mm})$ & $45 / 85 / 125 / 160 / 490$ \\
Wrap of $4^{\text {th }}$ cabling stage $(\mathrm{mm})$ & $0.05(\mathrm{SS} 304)$ \\
Wrap of last cabling stage $(\mathrm{mm})$ & $0.1(\mathrm{SS} 304)$ \\
Central spiral ID $\mathrm{OD}(\mathrm{mm} \times \mathrm{mm})$ & $10 \times 12(\mathrm{SS} 304)$ \\
Cable outer diameter $(\mathrm{mm})$ & 38 \\
Jacket material & SS $316 \mathrm{LN}$ \\
External dimensions $(\mathrm{mm} \times \mathrm{mm})$ & $50.3 \times 50.3$ \\
\hline
\end{tabular}

\section{TEST PROGRAM}

The PFI, delivered to JAEA, Naka in September 2007, was installed in the CSMC in the first quarter of 2008 [18], and tested from mid June till mid August 2008. The test program executed on the PFI reflected previous experience on CS Model Coil and Model Coil Inserts [19], [20], with the necessary adaptations to the different operating conditions and PF conductor characteristics [15]. Besides the obvious characterization of the DC and AC conductor performance once wound in a coil of relevant length and size, the main test focus was on the following items:

- sudden quenches. Short sample tests in SULTAN [5] had shown that above a current threshold ranging from 38 to 45 $\mathrm{kA}$, the quench current of the PFI CICC was much below the expected strand critical current. This was attributed to the combination of the magnetic and electric field gradient in the large cross section of the cable, uneven current distribution in the short sample, impressed by the joint [21], and poor current redistribution. The nominal design point of the ITER PF coils is above this threshold, and it was hence very important to check the quench current and temperature margin in a geometry close to that of a PF coil and with improved joint design;

- intermediate joint resistance and AC loss. A relatively high resistance $(10 \mathrm{n} \Omega)$ was observed during the test of the prototype joint in the short sample described above. This was attributed to the materials selected (CuCrZr sleeve) and joint assembly procedure (strand coating removal and soldering) in the preparation of the sample [5], [22]. Improvements in the base material conductance (by overaging at $550^{\circ} \mathrm{C}$ the sleeves) and joint technique were expected to reduce the resistance to an acceptable value for operation, around $5 \mathrm{n} \Omega$. The AC loss in the joint was not measured previously, nor its stability in pulsed field conditions, both factors of relevance for operation;

- AC loss characteristics of the conductor and variations with cycling. The coupling loss measured in a short piece of the final conductors $(400 \mathrm{~mm})$ was found to be a strong function of the number of mechanical loading cycles under a transverse force of $315 \mathrm{kN} / \mathrm{m}$ [13], which is in the range of the maximum expected mechanical load from Lorentz forces in the ITER PF coils ( 270 to $330 \mathrm{kN} / \mathrm{m}$ ). The initial product of demagnetization factor and coupling time constant $n \tau$, around $15 \mathrm{~ms}$ in virgin state, decreased to less than $10 \mathrm{~ms}$ in the first 100 cycles, to increase again above $40 \mathrm{~ms}$ after 10,000 cycles. These results could be only partially confirmed by short sample tests in SULTAN, where a monotonic decrease was measured over a smaller range of cycles. AC loss, and cable coupling in transverse field in 
particular, is a dominating source of heat in the ITER PF coils. A large part of the PFI test was hence dedicated to the measurement of the cable AC loss vs. cyclic loading.

More details on the genesis and finalization of the test program can be found in [15]-[17].

\section{CRitical CurRent and Temperature Margin}

\section{A. DC Measurements}

The critical current and operating margin of the PFI CICC was verified by over $20 \mathrm{~T}_{\mathrm{CS}}, \mathrm{T}_{\mathrm{C}}, \mathrm{I}_{\mathrm{C}}$ and $\mathrm{B}_{\mathrm{CS}}$ measurements. $\mathrm{T}_{\mathrm{CS}}$ measurements were performed ramping the CSMC and PFI to pre-defined currents, and varying the temperature in small steps (typically less then $0.1 \mathrm{~K}$ ) using the resistive heaters placed at the inlet of the cooling circuits. The conditions at each temperature step were held for a time duration sufficiently long (typically 5 minutes and longer) for the PFI to reach steady state conditions. The $\mathrm{T}_{\mathrm{C}}$ measurements were analogous to $\mathrm{T}_{\mathrm{CS}}$, but the PFI current was $20 \mathrm{~A}$. $\mathrm{I}_{\mathrm{C}}$ tests consisted in charging the CSMC to a predefined current (and corresponding background field), setting the inlet temperature of the PFI, ramping the PFI to a current well below the expected quench limit (typically $10 \mathrm{kA}$ below $\mathrm{I}_{\mathrm{C}}$ ), waiting a time sufficiently long to reach steady state, and ramping to quench at a speed of $1 \mathrm{kA} / \mathrm{min}$. We also performed a current sharing field run, $\mathrm{B}_{\mathrm{CS}}$, in which the temperature and PFI current was set, and the CSMC current was ramped at $1 \mathrm{kA} / \mathrm{min}$ (which corresponds to a central field ramp-rate of $4.7 \mathrm{mT} / \mathrm{s}$ ) to determine the background field at which the PFI quenches. The complete summary of these tests is reported in Table VI, where for each shot we have reported the type of run, the set CSMC current, the set $\left(\mathrm{T}_{\mathrm{CS}}, \mathrm{T}_{\mathrm{C}}\right.$ and $\mathrm{B}_{\mathrm{CS}}$ runs) or measured $\left(\mathrm{I}_{\mathrm{C}}\right.$ runs) PFI current, the computed peak field in the PFI $\mathrm{CICC}$, the measured temperature at the central joggle in the PFI main winding, and the temperature uncertainty obtained as half the range between minimum and maximum measured temperatures at all thermometers in the main winding, including inlet and outlet.

We remark first that the consistency among different types of measurements of the same critical point is excellent. Compare as an example shots 25-1 and 27-1 (representative of the nominal $45 \mathrm{kA}, 6 \mathrm{~T}$ operating point in the original PF6 design), or shots 28-1 and 30-1 (representative of the sub-cooled operation mode in PF6). Once translated in temperature margin, the difference between $\mathrm{T}_{\mathrm{CS}}$ and $\mathrm{I}_{\mathrm{C}}$ runs is less than $30 \mathrm{mK}$.

The second, very important remark is that the quench point (in terms of temperature, current or field) is very close to the expected conductor performance obtained as the sum of the critical current (at $10 \mu \mathrm{V} / \mathrm{m}$ ) of the single strands evaluated at the peak field in the conductor. The intuitive reason for this result is that in the case of $\mathrm{Nb}$ - $\mathrm{Ti}$ the superconductor operates close to $\mathrm{T}_{\mathrm{C}}$ and $\mathrm{B}_{\mathrm{C}}$, which implies a sharp voltage-temperature and voltage-field characteristic. The resistive transition starts at the peak field point of the conductor, and evolves into a thermal runaway with no measurable voltage, nor significant current redistribution. To give a quantitative evaluation of this statement we have reported in Fig. 1 the scatter plot of the measured vs. expected quench temperature. This last was computed as the current sharing temperature corresponding to the combination of operating current and peak field at the moment of quench. This calculation is based on the scaling of [23] applied to the set of
TABLE VI

SUMMARY OF $\mathrm{T}_{\mathrm{CS}}, \mathrm{T}_{\mathrm{C}}, \mathrm{I}_{\mathrm{C}}$ AND $\mathrm{B}_{\mathrm{CS}}$ RUNS

\begin{tabular}{ccccccc}
\hline Shot & type & $\begin{array}{c}\mathrm{I}_{\text {CSMC }} \\
(\mathrm{kA})\end{array}$ & $\begin{array}{c}\mathrm{I}_{\mathrm{PFI}} \\
(\mathrm{kA})\end{array}$ & $\begin{array}{c}\mathrm{B}_{\text {peak }} \\
(\mathrm{T})\end{array}$ & $\begin{array}{c}\mathrm{T} \\
(\mathrm{K})\end{array}$ & $\begin{array}{c}\delta \mathrm{T} \\
(\mathrm{K})\end{array}$ \\
\hline $10-1$ & $\mathrm{~T}_{\mathrm{C}}$ & 0 & 0.02 & 0 & 9.35 & 0.05 \\
$25-1$ & $\mathrm{~T}_{\mathrm{CS}}$ & 19.799 & 44.90 & 6.11 & 6.27 & 0.06 \\
$27-2$ & $\mathrm{I}_{\mathrm{C}}$ & 19.786 & 43.99 & 6.09 & 6.28 & 0.05 \\
$28-1$ & $\mathrm{~T}_{\mathrm{CS}}$ & 20.88 & 51.89 & 6.51 & 6.03 & 0.10 \\
$30-1$ & $\mathrm{I}_{\mathrm{C}}$ & 20.856 & 52.90 & 6.52 & 6.01 & 0.07 \\
$31-1$ & $\mathrm{I}_{\mathrm{C}}$ & 11.634 & 49.66 & 3.96 & 7.21 & 0.04 \\
$32-1$ & $\mathrm{I}_{\mathrm{C}}$ & 15.29 & 56.47 & 5.06 & 6.67 & 0.07 \\
$35-1$ & $\mathrm{~T}_{\mathrm{CS}}$ & 19.04 & 54.92 & 6.06 & 6.22 & 0.05 \\
$44-1$ & $\mathrm{I}_{\mathrm{C}}$ & 13.1 & 25.89 & 3.98 & 7.33 & 0.02 \\
$45-1$ & $\mathrm{~T}_{\mathrm{CS}}$ & 21.2 & 17.99 & 6.07 & 6.46 & 0.04 \\
$46-1$ & $\mathrm{~T}_{\mathrm{C}}$ & 22.1 & 0.02 & 6.03 & 6.80 & 0.04 \\
$48-1$ & $\mathrm{I}_{\mathrm{C}}$ & 16.85 & 29.60 & 5.06 & 6.84 & 0.02 \\
$49-1$ & $\mathrm{~T}_{\mathrm{CS}}$ & 9.45 & 30.00 & 3.05 & 7.71 & 0.06 \\
$50-1$ & $\mathrm{I}_{\mathrm{C}}$ & 31.56 & 26.51 & 9.03 & 4.84 & 0.06 \\
$53-1$ & $\mathrm{~T}_{\mathrm{CS}}$ & 21.62 & 6.00 & 6.00 & 6.57 & 0.02 \\
$61-1$ & $\mathrm{I}_{\mathrm{C}}$ & 31.56 & 26.55 & 9.03 & 4.84 & 0.03 \\
$68-1$ & $\mathrm{I}_{\mathrm{C}}$ & 31.56 & 27.30 & 9.04 & 4.83 & 0.04 \\
$105-1$ & $\mathrm{I}_{\mathrm{C}}$ & 31.56 & 26.49 & 9.03 & 4.84 & 0.04 \\
$120-1$ & $\mathrm{I}_{\mathrm{C}}$ & 31.56 & 27.16 & 9.04 & 4.83 & 0.04 \\
$136-1$ & $\mathrm{I}_{\mathrm{C}}$ & 31.56 & 26.58 & 9.03 & 4.84 & 0.04 \\
$138-1$ & $\mathrm{I}_{\mathrm{C}}$ & 22.55 & 54.30 & 7.01 & 5.73 & 0.06 \\
$145-1$ & $\mathrm{~B}_{\mathrm{CS}}$ & 18.77 & 45.00 & 5.83 & 6.40 & 0.02 \\
$146-1$ & $\mathrm{I}_{\mathrm{C}}$ & 28.72 & 44.02 & 8.53 & 4.99 & 0.05 \\
$148-1$ & $\mathrm{I}_{\mathrm{C}}{ }^{(1)}$ & 28.902 & 30.00 & 8.36 & 5.00 & 0.06 \\
$157-1$ & $\mathrm{~T}_{\mathrm{CS}}$ & 19.6 & 45.00 & 6.06 & 6.25 & 0.12 \\
\hline & & & & & & \\
& & & & & &
\end{tabular}

(1) this run was performed at PFI ramp-rate of $300 \mathrm{kA} / \mathrm{min}$

strand $I_{C}(B, T)$ data from [7]-[11]. The calculation matches the DC quench limit to a very good accuracy, with an average error of $50 \mathrm{mK}$ on the temperature margin, compatible with our estimate of the error bar on the evaluation of the local temperature at the quench point. The only exception to this behavior are Shots 58-1 (not reported in Table VI) and 148-1. The first one is a quench that occurred during a verification of the ramp-rate cycling conditions, and the second an $\mathrm{I}_{\mathrm{C}}$ measurement, both performed at the maximum PFI ramp-rate allowed by the test set-up of $5 \mathrm{kA} / \mathrm{s}$. Among these two shots, only 148-1 was performed in controlled conditions, thus allowing an analysis of the quench origin and a proper determination of the quench current. In this case we observed a degradation of the order of $0.15 \mathrm{~K}$, a small but appreciable effect (see the point labeled in Fig. 1).

An analysis of the characteristics of the voltage transition (smooth or sudden, depending on the operating current), and on the origin of the ramp-rate dependence observed, is in progress and will be reported at a later stage.

\section{STABILITY AND QUENCH}

The stability of the PFI CICC was measured by using one of the two inductive heaters placed in the joggle in the midplane of the main winding (peak CSMC field region). The inductive heater is a $102 \mathrm{~mm}$ long solenoid wound around the conductor, and it generates a field component parallel to the CICC varying at a frequency of $1 \mathrm{kHz}$. The calibration of the energy deposited by the heater was performed in a dedicated test [24] on a short piece of conductor as well as on a piece of cable and a piece of jacket separately. The energy from a pulse is mainly deposited 


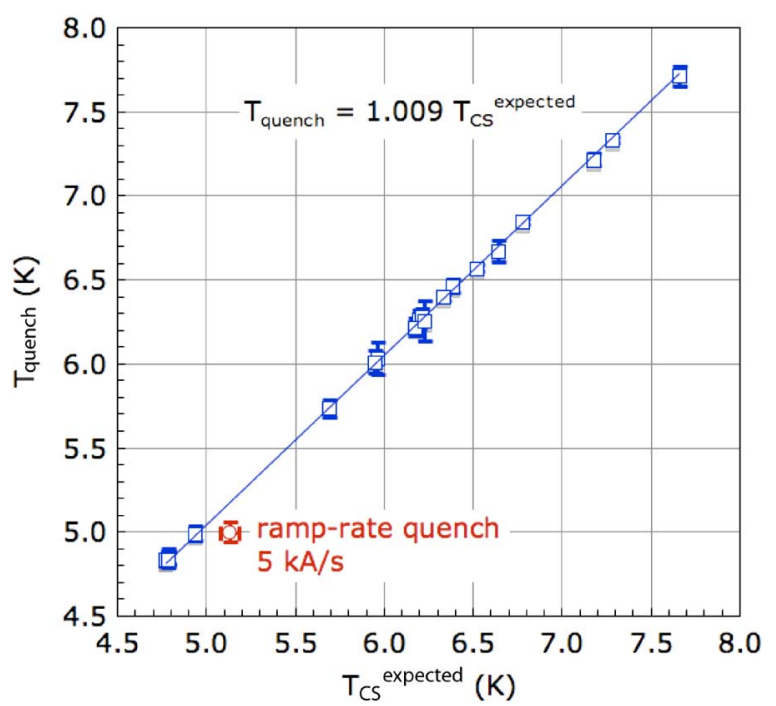

Fig. 1. Measured quench temperature vs. expected current sharing temperature for the complete set of $T_{C S}, I_{C}$ and $B_{C S}$ runs in the main winding of the PFI. The result for the ramp-rate shot $148-1$ is shown for comparison.

TABLE VII

SUMMARY OF STABILITY SHOTS

\begin{tabular}{ccccccc}
\hline Shot & $\begin{array}{c}I_{O P} \\
(\mathrm{kA})\end{array}$ & $\begin{array}{c}B_{O P} \\
(\mathrm{~T})\end{array}$ & $\begin{array}{c}T_{O P} \\
(\mathrm{~K})\end{array}$ & $\begin{array}{c}\Delta t_{P U L S E} \\
(\mathrm{~ms})\end{array}$ & $\begin{array}{c}\Delta E \\
(\mathrm{~J})\end{array}$ & $\begin{array}{c}\Delta t_{\text {quench }} \\
(\mathrm{s})\end{array}$ \\
\hline $108-5$ & 45 & 6 & 5.5 & 40 & $25.5 \pm 5$ & 1.5 \\
$110-7$ & 45 & 6 & 4.5 & 40 & $48.6 \pm 3.1$ & 2.5 \\
$111-5$ & 52 & 6.4 & 4.5 & 40 & $36.1 \pm 2.5$ & 1.9 \\
$112-18$ & 45 & 6 & 4.5 & 10 & $79.6 \pm 3.7$ & 0.9 \\
$115-4$ & 52 & 6.4 & 4.5 & 10 & $38.3 \pm 1.9$ & 1.6 \\
\hline
\end{tabular}

in the jacket, $85 \%$ of the total, while the remainder, $15 \%$ of the total, is deposited in the cable. This situation is not representative of energy release in the ITER PF coils, but provides a well known calibration for comparison with analytical and numerical estimates, and a suitable mechanism for quench initiation.

All stability and quench runs started from steady state operating conditions and approaching the stability/quench boundary from below. The inductive heater was fired after a relaxation time sufficient to reach uniform temperature in the coil (typically 5 minutes), and the transient recorded. In case of stable response, the energy setting of the heater was increased empirically, and the procedure repeated till quench. These stability and quench measurements were performed varying parametrically the operating current ( $45 \mathrm{kA}$ and $52 \mathrm{kA}$ ), the peak field (6 T and $6.4 \mathrm{~T})$, the operating temperature $(4.5 \mathrm{~K}$ and $5.5 \mathrm{~K})$ and the heating time ( $10 \mathrm{~ms}$ and $40 \mathrm{~ms})$. In Table VII we have reported the energy margin $\Delta E$, defined as the average of the highest stable energy and the lowest quench energy, vs. the operating and pulsing conditions tested. The energy reported is the total deposited by the heater on the conductor (i.e. cable and jacket). The shot number in Table VII corresponds to the quench, for which we have also reported the delay between the start of the inductive heating and the detection of a voltage across the voltage taps covering the location of the heater.

There is a relatively long delay between the heating pulse and the start of the quench, which is consistent with the fact that most of the power is deposited in the jacket of the CICC, and is slowly transferred to the cable either through direct contact or heat exchange in the helium. The stability margin has the expected qualitative dependence on the operating current and temperature. For operation at $52 \mathrm{kA}, 6.4 \mathrm{~T}$ and $4.5 \mathrm{~K}$ the margin does not depend on the heating time (compare shots 111-5 and $115-4)$, while at $45 \mathrm{kA}, 6 \mathrm{~T}, 4.5 \mathrm{~K}$ we observed a strong dependency. Specifically, the CICC seems to be much more stable to a pulse of $10 \mathrm{~ms}$ (shot 112-18) than to a pulse of $40 \mathrm{~ms}$ (shot 110-7). Note that shot $112-18$ is the one with the shortest delay between pulse and quench, which may indicate a change in heat transfer regime at the higher heating power used. We will comment further below, discussing initial quench propagation.

In each of the quench shots, the quench evolution was recorded at constant current and field for a time $\Delta t_{\text {evolution }}$ in the range of 6 to $7 \mathrm{~s}$, consisting in a detection time of 1 to $2 \mathrm{~s}$ necessary for the resistive voltage to increase above the detection threshold (set at $100 \mathrm{mV}$ ) and a quench delay time, set at $5 \mathrm{~s}$ for quenches at $45 \mathrm{kA}$ and $4 \mathrm{~s}$ for quenches at $52 \mathrm{kA}$. After this time, the PFI power supply was switched, and the current dumped.

A representative sample of the evolution of voltage is shown in Fig. 2 for the quench shot 115-4, at $52 \mathrm{kA}, 6.4 \mathrm{~T}, 4.5 \mathrm{~K}$ and $10 \mathrm{~ms}$ heating time. An interesting feature is that the voltage seen by voltage taps VD0809 and VD1011, covering the conductor section just before and just after the inductive heater, start showing a resistive voltage much earlier than the knee observed on voltage tap VD0910, spanning the heated region. The knee corresponds to the time when the whole conductor length is normal, at which time the voltage increase seen by the voltage tap is only driven by the temperature rise. The fact that the neighboring voltage taps react before the whole central section is normal suggests that the initial propagation of the quench takes place very inhomogeneously in the cable cross section. In particular, the propagation along the strands, possibly in a whole "petal" (the last-but-one cabling stage with wraps), is initially faster than the propagation in the cable cross section, and the quench hits the neighboring voltage taps before filling the whole cable cross section. This is no longer the case for the voltage rise in the next neighbors that happens at a time close to the knee of the voltage curves in the previous taps (see as a clear example in Fig. 2 the case of VD0708 flattening at about $5 \mathrm{~s}$, followed by the rise of the neighboring voltage tap VD0607). After the initial phase, the quench is well developed and appears to propagate as expected as a flat front in the cable cross section.

The evolution of the normal zone for all stability shots is reported in Fig. 3. Quenches at $52 \mathrm{kA}, 6.4 \mathrm{~T}$ and $45 \mathrm{kA}$ (shots 111-5 and 115-4) have the same evolution, which is consistent with the fact that the energy necessary to initiate the quench is the same in both cases. In contrast, quenches at $45 \mathrm{kA}, 6 \mathrm{~T}$ and $4.5 \mathrm{~K}$ initiated by much different energies (shots 110-7 and 112-18) are very different. Shot 112-18, initiated with a short pulse of $10 \mathrm{~ms}$ and higher energy, has an initial propagation that is much faster than shot 110-7, initiated by a longer pulse of $40 \mathrm{~ms}$ and lower energy. This result suggests that the energy in shot 112-18 affects a longer conductor length than in shot $110-7$, which is consistent with the significantly larger stability margin measured for shorter heating time. Finally, shot 108-5, measured for initial operation at $45 \mathrm{kA}, 6 \mathrm{~T}$ and $5.5 \mathrm{~K}$, has initial evolution comparable to that of the high current/high field 


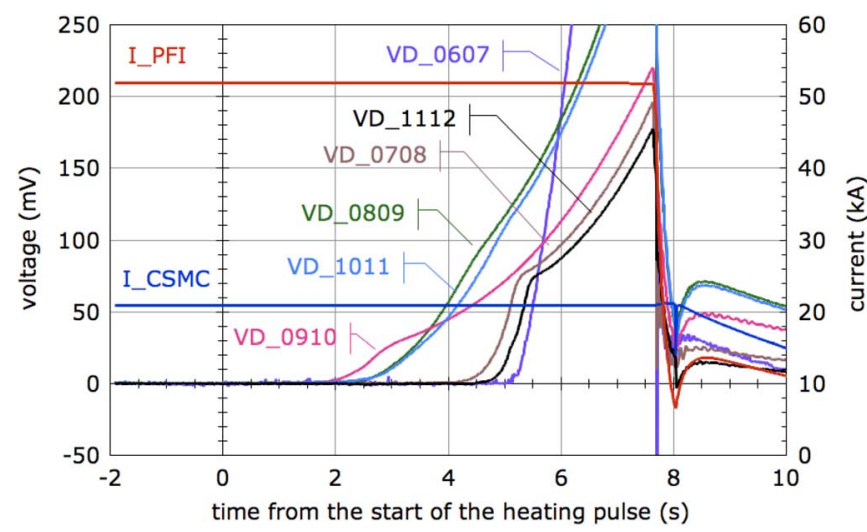

Fig. 2. Voltage recorded in the voltage taps covering the inductive heater (VD0910), and the next neighbors during quench shot 115-4.

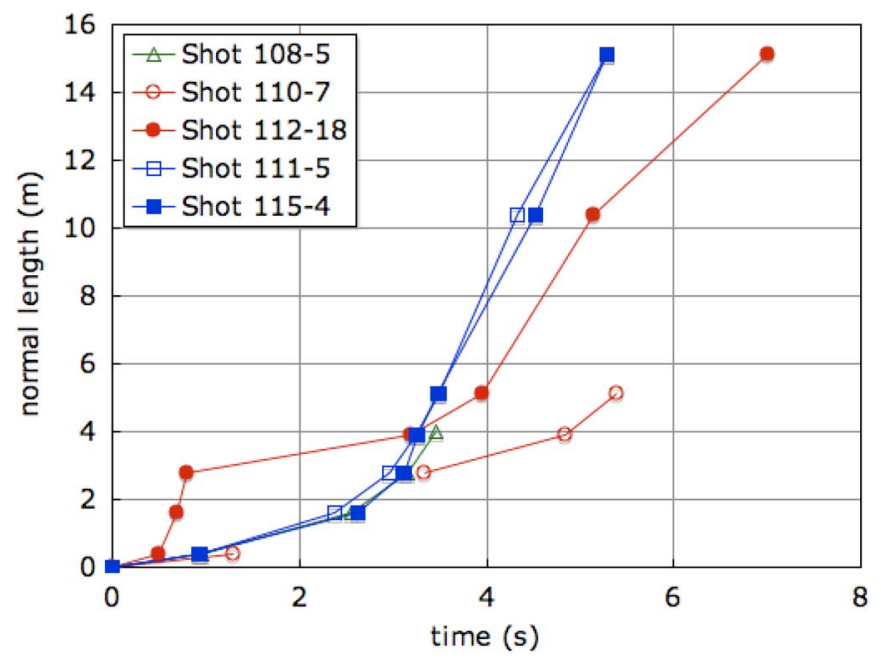

Fig. 3. Normal zone as a function of time for all quench shots. The origin of time corresponds to the appearance of a quench voltage in the voltage tap covering the inductive heater section.

quenches. This result is consistent with the expectation of faster quench propagation for smaller operating margin. The evolution of this quench could only be measured up to $3.5 \mathrm{~s}$ because of a dump trigger generated by the massflow quench detectors.

We report in Table VIII a compilation of relevant quantities for quench, i.e. the hot spot temperature $T_{h o t}$, the maximum pressure $p_{\max }$, and the length of the normal zone $L_{\text {normal }}$, all measured or computed at the time $\Delta t_{\text {evolution }}$ after the beginning of the quench, and just before dump. The hot spot temperature was derived from the resistive voltage in the voltage tap VD_0910 (centered around the inductive heater) assuming that the whole cable length is normal, current flows in the copper only, and using the known relation between cable resistance and temperature. As shown in Fig. 4, the hot-spot temperature is found to be in very good agreement with an adiabatic evaluation based on the copper and superconductor cross section, neglecting the heat transfer to the helium and jacket. This result confirms the presence of significant temperature gradients in the cable cross section (cable to helium and cable to jacket). Similar values of temperature are found analysing the voltage of the neighboring voltage taps (see again Fig. 4), although in this
TABLE VIII

MAIN RESULTS OF QUENCH EVOLUTIONS

\begin{tabular}{ccccc}
\hline Shot & $\begin{array}{c}\Delta t_{\text {evolution }} \\
(\mathrm{s})\end{array}$ & $\begin{array}{c}T_{\text {hot }} \\
(\mathrm{K})\end{array}$ & $\begin{array}{c}p_{\max } \\
(\mathrm{bar})\end{array}$ & $\begin{array}{c}L_{\text {normal }} \\
(\mathrm{s})\end{array}$ \\
\hline $108-5$ & 4.23 & 58 & 9.1 & 4 \\
$110-7$ & 6.53 & 81 & 10.3 & 5.1 \\
$111-5$ & 5.7 & 100 & 22.8 & 15.1 \\
$112-18$ & 7.48 & 93 & 15.0 & 15.1 \\
$115-4$ & 5.66 & 100 & 22.3 & 15.1 \\
\hline
\end{tabular}

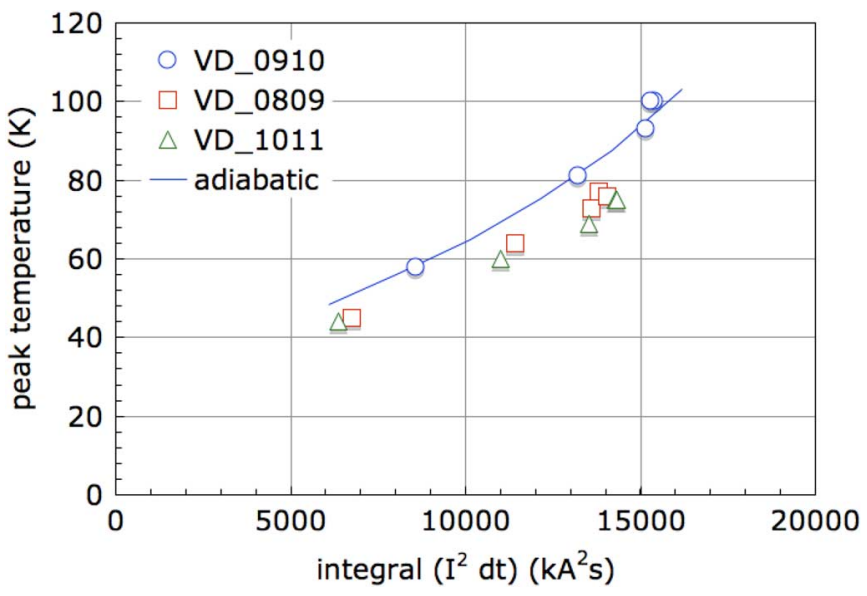

Fig. 4. Hot spot temperature deduced from the measured voltage in the pair of voltage taps covering the inductive heater section (VD_0910), and simulated assuming adiabatic conditions (superconductor and copper cross sections). The temperature values are plotted vs. the time integral of the square of current, for all shots in Table VIII. Also reported for comparison the temperature deduced from the neighboring voltage taps.

case the presence of a longitudinal temperature gradient yields somewhat lower average temperatures, as expected.

\section{Conductor AC Loss Measurements}

The AC loss of conductor and joint was measured at zero current in the PFI, and varying the field generated by the CSMC. Two field waveforms were used: an exponential dump of the CSMC from different initial currents and with $6 \mathrm{~s}$ time constant, and trapezoidal ramps with variable flat-top field and ramp-rate. The measurement of the AC loss energy was mainly based on calorimetry, using the thermometers in the cooling paths and in the winding. Data from the pick-up coils placed on the conductor and on the joint could be only partially analysed at the time of writing. So far an absolute calibration of the electrical measurements is not available and hence we expect only a qualitative confirmation of the calorimetric result. The accuracy of calorimetry was verified by a series of dedicated heat slug runs (shots 4-1 to 4-7). It was found that in the expected range of energy input ( $1 \mathrm{~kJ}$ to $10 \mathrm{~kJ}$, depending on the field variation) the energy balance had a systematic error of $-6 \%$ and an uncertainty of $\pm 110 \mathrm{~J}$. This could be confirmed by cross correlation of calorimetric evaluations of the $\mathrm{AC}$ loss shots at various thermometers in the winding.

A total of $38 \mathrm{AC}$ loss measurement shots were performed at various stages during the test. A summary of the evaluation of the conductor loss in the main winding, quoted in terms of the coupling loss product $n \tau$, is shown in Fig. 5. The loss was measured before applying any significant Lorentz force to the conductor and before any quench, using exponential field dumps from a set field of 4 or $6 \mathrm{~T}$ in the CSMC. The virgin value of 


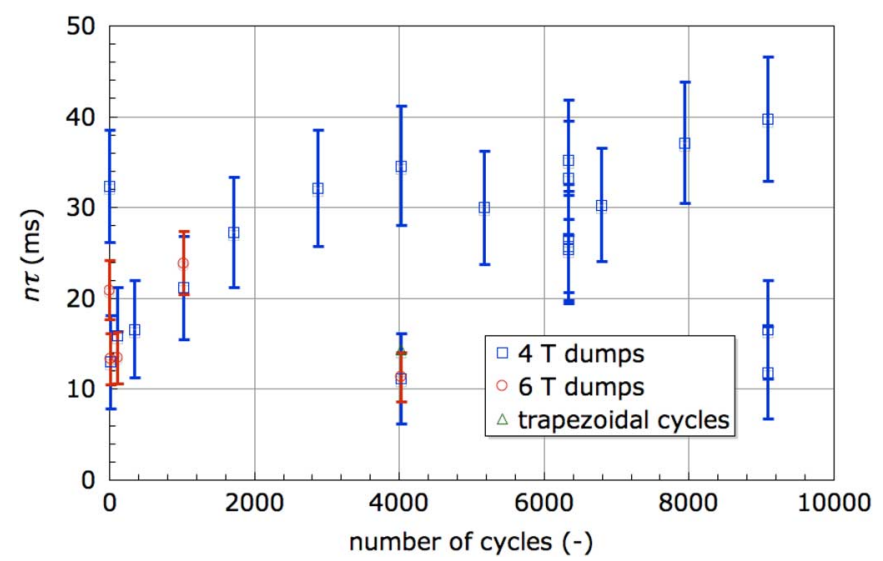

Fig. 5. Value of the product of cable demagnetization and coupling time constant, $n \tau$, evaluated from loss measurements during the whole test campaign of the PFI, as a function of the load cycles. The first drop in $n \tau$ after 4020 load cycles corresponds to the situation after the stability and quench shots. The scattered results at 6330 load cycles corresponds to variation in the measurement conditions and procedure. The last drop, after 9080 load cycles, corresponds to the situation after high field quenches at the end of the cycling.

TABLE IX

SUMMARY OF $\mathrm{T}_{\mathrm{CS}}$, AND $\mathrm{I}_{\mathrm{C}}$ RUNS FOR THE MEASUREMENT OF THE MARGIN IN THE INTERMEDIATE JOINT

\begin{tabular}{ccccccc}
\hline Shot & type & $\begin{array}{c}\mathrm{I}_{\mathrm{CSMC}} \\
(\mathrm{kA})\end{array}$ & $\begin{array}{c}\mathrm{I}_{\mathrm{PFI}} \\
(\mathrm{kA})\end{array}$ & $\begin{array}{c}\mathrm{B}_{\text {peak }} \\
(\mathrm{T})\end{array}$ & $\begin{array}{c}\mathrm{T} \\
(\mathrm{K})\end{array}$ & $\begin{array}{c}\delta \mathrm{T} \\
(\mathrm{K})\end{array}$ \\
\hline $34-1$ & $\mathrm{I}_{\mathrm{C}}$ & 22.55 & 50.93 & 5.19 & 5.99 & 0.15 \\
$142-1$ & $\mathrm{~T}_{\mathrm{CS}}$ & 15.97 & 45 & 3.77 & 6.29 & 0.01 \\
$143-1$ & $\mathrm{~T}_{\mathrm{CS}}$ & 20.7 & 52 & 4.80 & 5.84 & 0.04 \\
$149-1$ & $\mathrm{~T}_{\mathrm{CS}}$ & 24.05 & 30 & 5.19 & 5.63 & 0.01 \\
$155-1$ & $\mathrm{I}_{\mathrm{C}}$ & 32.5 & 47.05 & 7.10 & 4.22 & 0.10 \\
$156-1$ & $\mathrm{~T}_{\mathrm{CS}}$ & 9.2 & 10 & 1.97 & 7.23 & 0.13 \\
\hline
\end{tabular}

the product $n \tau$ for the conductor in the main winding is evaluated in the range of $30 \pm 6 \mathrm{~ms}$. This value decreased to $14 \pm$ $5 \mathrm{~ms}$ after the first powering and quenches of the PFI together with the CSMC (equivalent to about 10 full load cycles). Trapezoidal cycling at $30 \mathrm{kA}$, in a background field of approximately $8 \mathrm{~T}$, i.e. with Lorentz forces comparable to those experienced in the normal operating conditions for ITER, led to a steady increase of the product $n \tau$ up to $37 \pm 7 \mathrm{~ms}$ after 4020 load cycles. At this point we performed the stability and quench experiments described earlier, and we observed a sharp drop of $n \tau$ to $12 \pm 5 \mathrm{~ms}$, i.e. a value close to the one obtained after the initial quenches. After further 1155 load cycles the value increased rapidly back to $33 \pm 6 \mathrm{~ms}$, i.e. the value before the stability and quench tests. Subsequent tests were performed varying the test conditions, and in particular the initial mass flow and temperature, and the field cycle leading to the dump. The range of variability observed in the following results indicates that the envelope of operating conditions, field cycles and any measurement artifacts, results in an uncertainty of $10 \mathrm{~ms}$ on the estimated $n \tau$. The highest value measured for $n \tau$, obtained after 9080 load cycles, is $43 \pm 7 \mathrm{~ms}$. Relaxation and quenching may further influence these results. We witnessed this effect when re-measuring $\mathrm{AC}$ loss after the end of the cycling and two high field quenches, yielding a $n \tau$ of $19 \pm 5 \mathrm{~ms}$.

Although there is a clear need for further critical analysis of these results, the values of $n \tau$ obtained are consistent with a

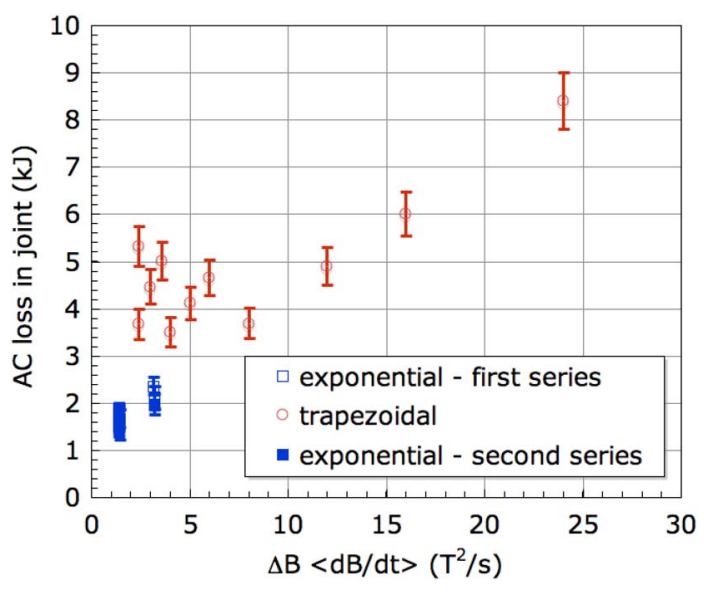

Fig. 6. AC loss in the intermediate joint, plotted for all runs as a function of the product of the field change times the average field change rate.

saturation value below $50 \mathrm{~ms}$ after a very large number of load cycles, which is well within the allocated budget of $100 \mathrm{~ms}$.

\section{INTERMEDIATE JOINT}

The joint resistance was measured systematically during the test campaign using the voltage taps across the joint terminations. Measurements were performed from $10 \mathrm{kA}$ to $55 \mathrm{kA}$, and for background fields at the location of the joint $B_{I J}$ in the range of $0 \mathrm{~T}$ to $5 \mathrm{~T}$. In this range the value of the joint resistance $R_{I J}$ was found to be:

$$
R_{I J}=2.03+0.057 B_{I J} \pm 0.14 \mathrm{n} \Omega
$$

with no dependence on time or powering history during the test. This value is much improved with respect to the one obtained on the SULTAN short sample $(\approx 10 \mathrm{n} \Omega)$ as well as the expectation after the design and manufacturing improvements $(\approx 5 \mathrm{n} \Omega)$.

The possibility of heating independently the intermediate joint using either the facility heaters on the inlet cooling lines, or the resistive heaters directly applied on the joint, has allowed us to measure the quench current and temperature of the joint itself. Table IX reports the values of the quench current and temperature evaluated during these shots, defined as for the test of the main winding as the values of current and temperature at the joint leading to a thermal runaway. With respect to the conductor properties, using the same analysis as described for the data in Fig. 1, there is an apparent degradation of the temperature margin at the intermediate joint of about 0.7 to $1.5 \mathrm{~K}$. Although this is not critical for the performance of the coil, it is important to understand its origin, whether caused by a measurement artifact (e.g. a local temperature gradients not seen at the helium thermometers), or inherent to the joint itself.

The AC loss of the intermediate joint was deduced from the same calorimetric balance used to establish the conductor AC loss. A summary of the loss results is reported in Fig. 6. The measured loss has been plotted there as a function of the product of the field change $\Delta \mathrm{B}$ times the average field change rate over the excitation waveform $\langle\mathrm{dB} / \mathrm{dt}\rangle$, which equals the integral of the square of $\mathrm{dB} / \mathrm{dt}$ over the excitation time. The loss energy deposited in the joint during an exponential dump of the CSMC from a field of $4 \mathrm{~T}$ and with a time constant of approximately 
$6 \mathrm{~s}$ (initial $\mathrm{dB} / \mathrm{dt}$ of $0.67 \mathrm{~T} / \mathrm{s}$ ) is $1670 \pm 80 \mathrm{~J}$, while for an exponential dump of the CSMC from a field of $6 \mathrm{~T}$, and $6 \mathrm{~s} \mathrm{dump}$ time constant (initial $\mathrm{dB} / \mathrm{dt}$ of $1 \mathrm{~T} / \mathrm{s}$ ), the measured loss is 2140 $\pm 160 \mathrm{~J}$. For exponential dumps and high ramp-rate trapezoidal ramps, the loss seems to scale linearly with $\Delta \mathrm{B}\langle\mathrm{dB} / \mathrm{dt}\rangle$, as would be expected for eddy currents loss at low excitation frequency. In the case of trapezoidal ramps at modest ramp-rate, the results are affected by a large spread. Unstable magnetization signals were observed in the same range of excitation, which could explain at least some of the observed instability.

\section{CONCLUSIONS}

The PFI coil test was highly satisfactory as regards achievement of its main objectives, i.e. the establishment of a large database of experimental data relevant to the ITER PF coils. The assessment of the data collected is not yet complete, only few days after the end of the test campaign, and more analysis is definitely required to complete the picture drawn here. Nonetheless, already at this preliminary stage of the analysis, we see that most results match closely the expectations, and thus provide excellent confidence that the ITER PF coils will meet their performance requirements.

Specifically, the coil limits were found to be identical to the sum of the strand performances in the cable at the location of the peak magnetic field, and there was no sign of any training or fatigue effects. Most important, the coil performance at the nominal design current ( $45 \mathrm{kA}$ to $52 \mathrm{kA}$ ) was not affected by the premature quenches observed on short cable samples [5]. This result supports our understanding that the quench performance of short cable samples at high current is affected by the current distribution impressed by the joints [21], and an extrapolation to long lengths is not trivial.

Although pulse testing of the coil at high voltage was limited, sufficiently accurate assessments of the AC loss of the conductor and joint were obtained during fast discharges. These confirmed that the asymptotic value of the coupling loss constant $n \tau$ is of the order of $50 \mathrm{~ms}$, in the range of the value expected from measurements on short samples [13] and well within the range acceptable from the point of view of heat removal.

Finally, the coil was powered to conditions corresponding to an electromagnetic load $50 \%$ in excess of the design values (Shot $155-1, \mathrm{~B} \times \mathrm{I} \approx 450 \mathrm{kN} / \mathrm{m}$ ) without showing any sign of mechanical or electrical degradation in the following shots.

\section{ACKNOWLEDGMENT}

The work reported here is the fruit of a collaboration among the RF Institutes VNIIKP and VNIINM (strand and cable manufacture), European Commission, EFDA CSU Garching and EU Fusion Associations (jacketing and manufacture of the PFI coil) and JAEA-Naka (installation and test) within the scope of the ITER-EDA Agreement. The authors thank W. Baker, V. Pantsyrny, H. Rajainmäki, I. Rodin, E. Salpietro, R. Yoshino and members of ITER Superconducting Magnet Technology Group at JAEA.

\section{REFERENCES}

[1] N. Mitchell et al., "The ITER magnet system," IEEE Trans. Appl. Sup, vol. 18, pp. 435-440, 2008.

[2] N. Mitchell et al., "Improvements to the ITER magnets to extend the plasma operating window," presented at the 18th Topical Meeting on the Technology of Fusion Energy, San Francisco, Sep. 2008, to appear in Fusion Science and Technology, unpublished.

[3] Z. J. J. Stekly and J. L. Zar, "Stable superconducting coils," Tans. Nucl. Sci., p. 367, 1965.

[4] R. Wesche et al., "DC performance, AC loss and transient field stability of five medium size NbTi cable-in-conduit conductors with parametric variations on nbti abrupt quenches and current non-uniformity," Cryogenics, vol. 45, no. 12, pp. 755-779, 2005.

[5] P. Bruzzone et al., "Test results of the ITER PF insert conductor short sample in SULTAN," IEEE Trans. Appl. Sup., vol. 15, no. 2, pp. 1351-1354, 2005.

[6] C. Sborchia et al., "Design and manufacture of the ITER poloidal field conductor insert coil," Fus. Eng. Des., vol. 66-68, pp. 1081-1086, 2003.

[7] A. K. Shikov, Certificates of production of experimental 0.73-mm ITER strand based on NbTi alloy State Scientific Center of Russian Federation, VNIINM, unpublished.

[8] N. I. Kozlenkova et al., "Study on Ic(T,B) for the NbTi strand intended for ITER PF insert coil," IEEE Trans. Appl. Sup., vol. 14, no. 2, pp. 1028-1030, 2004.

[9] L. Zani et al., "Jc(T,B) characterization of NbTi strands used in ITER PF-relevant insert and full-scale sample," IEEE Trans. Appl. Sup., vol. 15 , no. 2, pp. 3506-3509, 2005.

[10] H. W. Weber et al., Analysis of PF conductor with high $\mathrm{Cu} / \mathrm{Non}-\mathrm{Cu}$ ratio Association EURATOM-OeAW, Atominstitut, Wien, Austria, Oct. 2007, Final Rep. Technol. Task TW5-TMSC-PFANAL (Contract No. 05-1326).

[11] N. I. Kozlenkova et al., "Jc(T,B) and $\mathrm{E}(\mathrm{T})$ dependencies for $\mathrm{NbTi}$ strands used in ITER PF insert coil," IEEE Trans. Appl. Sup., vol. 17, no. 2, pp. 2556-2559, 2007.

[12] W. Baker et al., "Manufacture of the poloidal field conductor insert coil (PFCI)," Fusion Engineering and Design, vol. 82, pp. 1567-1573, 2007.

[13] Y. A. Ilyin et al., "Effect of cyclic loading and conductor layout on contact resistance of full-size ITER PFCI conductors," IEEE Trans. Appl. Sup., vol. 15, no. 2, pp. 1359-1362, 2005.

[14] D. Ciazynsky et al., "DC performances of ITER NbTi conductors: Models vs. measurements," IEEE Trans. Appl. Sup., vol. 15, no. 2, pp. 1355-1358, 2005.

[15] R. Zanino et al., "Preparation of the ITER poloidal field conductor insert (PFCI) test," IEEE Trans. Appl. Sup., vol. 15, no. 2, pp. 1346-1350, 2005.

[16] R. Zanino et al., "Implications of NbTi short-sample test results and analysis for the ITER poloidal field conductor insert (PFCI)," IEEE Trans. Appl. Sup., vol. 16, no. 2, pp. 886-889, 2006.

[17] R. Zanino et al., "Predictive analysis of the ITER poloidal field conductor insert (PFCI) test program," IEEE Trans. Appl. Sup., vol. 17, no. 2, pp. 1353-1357, 2007.

[18] Y. Nunoya et al., "Installation and test programme of the ITER poloidal field conductor insert (PFCI) in the CSMC facility at JAEA Naka," presented at the ASC 2008, Chicago, Paper 2LPT02, submitted for publication.

[19] N. Martovetsky et al., "Test of the ITER central solenoid model coil and CS insert," IEEE Trans. Appl. Sup., vol. 12, no. 2, pp. 600-605, 2002.

[20] N. Martovetsky et al., "Test of the ITER TF insert and central solenoid model coil," IEEE Trans. Appl. Sup., vol. 13, no. 2, pp. 1441-1446, 2003.

[21] E. P. A. van Lanen and A. Nijhuis, "Simulation of the ITER poloidal field coil insert DC performance with a new model," presented at the 2008 Symposium on Fusion Technology, Rostock, unpublished.

[22] F. H. Hurd et al., "Design and manufacture of a full size joint sample (FSJS) for the qualification of the poloidal field (PF) insert coil," IEEE Trans. Appl. Sup., vol. 15, no. 2, pp. 1379-1382, 2005.

[23] L. Bottura, "A practical fit for the critical surface of NbTi," IEEE Trans. Appl. Sup., vol. 10, pp. 1054-1057, 2000.

[24] K. Matsui et al., Evaluation of inductive heating energy of PF insert coil conductor by calorimetric method 2008, JAEA-Technology-08, unpublished. 